\title{
Associations between shopping patterns, dietary behaviours and geographic information system-assessed store accessibility among small food store customers
}

\author{
Jared T McGuirt1,*, Qiang Wu², Melissa N Laska ${ }^{3}$, Kimberly P Truesdale ${ }^{4}$, \\ Ann P Rafferty ${ }^{5}$, Ronny A Bell ${ }^{5}$, Alice S Ammerman ${ }^{4}$ and Stephanie B Jilcott Pitts ${ }^{5}$ \\ 'Department of Nutrition, University of North Carolina Greensboro, 319 College Avenue, 318 Stone Building, \\ Greensboro, NC 27412, USA: ${ }^{2}$ Department of Biostatistics, East Carolina University, Greenville, NC, USA: ${ }^{3}$ Division \\ of Epidemiology and Community Health, University of Minnesota, Minneapolis, MN, USA: ${ }^{4}$ Department of Nutrition, \\ University of North Carolina at Chapel Hill, Chapel Hill, NC, USA: ${ }^{5}$ Department of Public Health, East Carolina \\ University, Greenville, NC, USA
}

Submitted 3 April 2020: Final revision received 12 0ctober 2020: Accepted 26 0ctober 2020: First published online 15 December 2020

\begin{abstract}
Objective: To examine associations between geographic information systems (GIS)-assessed accessibility to small food stores, shopping patterns and dietary behaviours among small food store customers.

Design: Residential addresses and customer shopping patterns (frequency of shopping, and previous purchase of fruits and vegetables) were gathered through customer intercept surveys. Addresses were geocoded, and GIS-assessed distance and driving time from the participants' residence to the store were calculated. Dietary status and behaviours were assessed using an objective non-invasive measure of skin carotenoids, the National Cancer Institute Fruit and Vegetable Screener, and items to assess sugary beverage intake. Associations between distance and driving time, demographics, shopping frequency, prior reported purchase of fruits and vegetables at the store and dietary behaviours were examined. Setting: Small food stores ( $n$ 22) across North Carolina.

Participants: Cross-sectional convenience samples of English-speaking customers aged 18 years or older ( $n$ 692).

Results: Participants living closer to the small store had lower income and formal education, were more likely to be Black, more likely to have previously bought fruits and vegetables at the store and more frequently shopped at the store. In adjusted models, skin carotenoids ( $n$ 644) were positively associated with distance to the store from home in miles $(P=0 \cdot 01)$.

Conclusions: Customers who lived closer to the stores were more frequent shoppers and more likely to have previously purchased fruits and vegetables at the store yet had lower skin carotenoids. These results support continued efforts to examine how to increase the availability and promotion of healthful foods at small food retail stores.
\end{abstract}

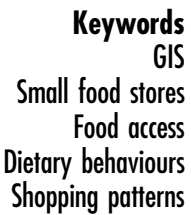

People living in food deserts have reduced access to affordable and nutritious food ${ }^{(1,2)}$. This reduced access can influence shopping habits and dietary patterns and potentially increase the risk of diet-related diseases ${ }^{(3,4)}$. Low-income, rural, and racial and ethnic minorities are often dually burdened with limited access to healthy foods and increased risk of diet-related morbidity and mortality $^{(1)}$. These compounding factors may be contributing to existing diet-related health disparities in these populations $^{(3)}$.
Small food stores, like convenience stores or corner stores, are a routinely accessed component of the retail food environment ${ }^{(5)}$ and have received increased attention as an opportunity to improve access to healthy foods ${ }^{(6-8)}$. These stores often carry less healthy foods and beverages, including processed foods with low nutrient density and added sugars ${ }^{(9,10)}$. The scarcity of healthy foods in small food stores may be exacerbated in rural areas and communities of colour ${ }^{(10,11)}$. Food options are often higher priced, but these stores are also often prevalent in 
low-income urban and rural locations, and thus more convenient, compared to full-service supermarkets ${ }^{(12,13)}$. For many people living in food deserts, and particularly for those with limited transportation, small food stores may be the sole food venue within a reasonable travel distance ${ }^{(13)}$.

The influence of access to corner stores on shopping and dietary behaviours remains relatively unclear, with intervention studies showing mixed results ${ }^{(6,8,14)}$, and observational epidemiology studies often using incomplete or inadequate measurements (e.g. non-road network Euclidean distance and inappropriate distance measures to account for complex travel patterns $)^{(3,15,16)}$. Relatively few studies have directly examined associations between distance from small food stores to participants' residential location, purchasing behaviours at specific small food stores, and dietary behaviours ${ }^{(3,17,18)}$. Understanding this relationship is important as efforts are made to increase healthy food options in small food stores.

Prior studies of the association between the food environment and dietary patterns have relied on recallbased dietary assessment measures which are subject to systematic bias and measurement error ${ }^{(19-21)}$. The emergence of a measurement tool to objectively, noninvasively and easily measure skin carotenoid status as an approximation of fruit and vegetable intake has provided a new opportunity to better understand associations between the food environment and dietary behaviours $^{(22)}$. Recent research has examined associations between the food environment and skin carotenoid status, finding that, even when controlling for individual-level variables related to income, age, sex and race/ethnicity, individuals living in areas with higher concentrations of convenience stores (i.e. stores that offer less healthful foods) had lower levels of skin carotenoids ${ }^{(18)}$. To our knowledge, no previous research has examined the associations between objectively assessed proximity to a small food store where customers were shopping, the frequency of shopping, previous purchase of fruits and vegetables at that store, the proportion of foods purchased at the store, and self-reported and objectively measured dietary behaviours. Examining these relationships can help elucidate the influence of accessibility to small food stores located in food deserts on dietary behaviours of customers shopping at the store and can further inform intervention efforts in small food stores. Thus, we sought to examine associations between geographic information systems (GIS)-assessed proximity to stores, customer shopping patterns and dietary behaviours among small food store customers. Distance to the store was hypothesised to be inversely associated with the frequency of shopping such that those who live close to the small food store shop there more frequently and thus purchase a larger proportion of foods/beverages from the small food store.

\section{Methods}

\section{Study settings and participants}

This analysis was conducted as part of a larger study evaluating the impact of the North Carolina Healthy Food Small Retailer Program (HFSRP) on healthy food availability, purchases and consumption ${ }^{(23)}$. The HFRSP was a grant programme to support retailers in stocking nutrient-dense foods (i.e. fresh vegetables and fruits, whole grains, nuts, seeds, beans and legumes, low-fat dairy products, lean meats, and seafood), including funding for refrigeration units and shelving. Data were collected from 22 stores in food deserts (determined using the United States Department of Agriculture (USDA) Food Access Research Atlas dataset ${ }^{(24)}$, with food deserts being defined as lowincome census tracts with a substantial number or share of residents with low levels of access to retail outlets selling healthy and affordable foods) across 14 rural- and urbandesignated counties in central and eastern North Carolina. Stores were selected as described previously ${ }^{(15)}$.

In brief, stores received HFSRP funding as part of a competitive application process. The study authors did not control the selection of the funded HFSRP stores. Control stores were selected through a matching process so that they would be as similar as possible to HFSRP-funded stores. The study team first matched the stores on a variety of store-level factors including North American Industry Code Standards (NAICS), store type (small grocery or convenience store), store size, and whether the store was located in a census tract that was designated as a USDA food desert (at least 500 persons and/or at least 33 per cent of the population lives more than 1 mile from a supermarket or large grocery store (10 miles, in the case of rural census tracts) ${ }^{(25)}$. For the control stores, the study team then matched on area demographics, including per cent of the census tract that received Supplemental Nutrition Assistance Program benefits and the per cent African American residents in the census tract. All store locations met square footage requirements of the legislation (less than 3000 square feet of heated space) and were authorised retailers in the Special Supplemental Nutrition Program for Women, Infants, and Children (or were willing to undergo authorisation). Some of the stores included a gas pump area, while others functioned as neighbourhood grocery stores. As part of the larger study evaluating the programme, data were collected on the food and beverage items offered at each store as well as customer purchasing and dietary behaviours. Participants were provided a $\$ 10$ gift card for their time.

Participants were recruited within small stores across 3 years (2017-2019), creating a cross-sectional sample for these analyses. Store customers were approached by research staff after completing their purchase (mostly between 8 am and $5 \mathrm{pm}$, Monday-Friday). To be eligible for the study, participants had to be 18 years of age or older 
and speak English. Participants received a study information sheet and provided verbal informed consent before data collection. The (anonymised) Institutional Review Board reviewed and approved study \#UMCIRB 16-002420. As part of the study, participants completed customer intercept surveys, permitted data collectors to perform bag checks in which the contents of their purchases were recorded and had their skin carotenoids status assessed using a reflection spectroscopy device (the Veggie Meter ${ }^{\circledR}$, Longevity Link Corp. $\left.{ }^{\mathrm{TM}}\right)^{(26)}$.

\section{Demographic and antbropometric data}

Demographic data collected included sex (male, female and other), age (years), race and ethnicity (American Indian or Alaska Native, Asian, Black or African American, Native Hawaiian or Pacific Islander, White, Other or Refused; Hispanic or Latino), highest grade completed in school, annual household income (less than $\$ 25000, \$ 25000$ to $\$ 50000, \$ 50000$ to $\$ 75000, \$ 75000+$ and not reported) and employment status (employed full-time, employed part-time, not employed and retired). We derived BMI $\left(\mathrm{kg} / \mathrm{m}^{2}\right)$ from the participant's self-reported height and weight.

\section{Customer and store-level geospatial data}

As part of the customer intercept survey, participants provided the physical address of their primary residence. Verified small food store addresses were obtained from Reference USA (InfoGroup, 2018; Papillion, NE, USA) business database. All addresses were batch-geocoded to the highest level of accuracy using the Google Maps application programming interface through the BatchGeo ${ }^{(27)}$ website. For additional verification, Google Maps street listings and Google satellite imagery were utilised (Google LLC, Mountain View, CA, USA). Participants with incomplete addresses (no information or street number not provided; the street name was misspelled and could not be determined; and address not found in the geodatabase) were removed from the dataset for this study ( $n$ 323/ $1015(31 \cdot 8 \%))$. Those with complete addresses shopped more frequently at the store $(P<.0001)$ and had higher sugary beverage consumption $(P=0 \cdot 01)$ compared to those without a complete address.

The distance (in miles and minutes) from the participants' residential address to the store where they were surveyed was calculated using the Environmental Systems Research Institute (ESRI) (Redlands, CA, USA) ArcGIS Online network analysis services. This approach uses road networks to simulate typical travel behaviours, particularly by motor vehicle transportation, thus providing a more accurate/realistic estimate of accessibility $v$. distance alone. For accuracy and to reduce edge effects (loss of information due to spatial administrative boundaries like county boundaries), potential participant travel paths along the road network were allowed to traverse administrative boundaries (i.e. county) using a North America-wide road network dataset. Along with physical distance, we generated a time cost variable using ESRI's predictive traffic modelling to capture the time needed to traverse the shortest road network path based on typical traffic conditions. Census tract-level rural $v$. urban designation for the small food stores and participants were obtained from the USDA Food Access Research Atlas dataset ${ }^{(24)}$ and spatially joined to each store using ArcMap.

\section{Customer shopping data}

Customer shopping data were collected by two mechanisms: customer recall of previous purchases and objective assessment of items purchased at the current visit (bag checks). To determine whether participants had previously purchased fruits and vegetables at the small food store, they were asked the following: 'Have you ever bought fresh fruits and vegetables from this store?' To determine the proportion of foods typically purchased at the store, customers were asked 'Please think about all the foods you eat and all the beverages you drink on a regular basis. About what proportion of all the food and beverages you consume comes from this corner store?' and were given the response options of 'All or most of my food and beverages', 'More than half', 'About half', 'Less than half' and 'A very small proportion of my food and beverages comes from this corner store'. This question was only asked for 2019 participants.

\section{Customer dietary data}

Customer dietary data were collected using both recallbased and objective measures. The customer intercept survey included the National Cancer Institute (NCI) Fruit and Vegetable (FV) Screener ${ }^{(28)}$, which includes frequency and amount for the following items: $100 \%$ juice (orange, apple, grape or grapefruit); fruit (fresh, canned, frozen and no juice); lettuce salad; French fries/fried potatoes; other white potatoes (baked, boiled, and mashed potatoes, potato salad, and white potatoes that were not fried); cooked dried beans; other vegetables; and tomato sauce (tomato sauce on pasta or macaroni, rice, pizza and other dishes). It also includes frequency for vegetable mixtures (foods such as sandwiches, casseroles, stews, stir-fry, omelets and tacos). We used the NCI's standard scoring algorithms to calculate FV servings per day ${ }^{(28)}$.

To determine sugar-sweetened beverage (SSB) intake, we used items adapted from the Behavioral Risk Factor Surveillance System survey ${ }^{(29)}$. Participants were asked about the frequency of 'regular soda' consumption (not including diet soda or diet pop) and sweetened fruit drink consumption (including Kool-Aid ${ }^{\circledR}$, cranberry and lemonade). Response options included never; 1-3 times/month; 
1-2 times/week; 3-4 times/week; 5-6 times/week; 1 time/d; 2 times/d; 3 times/d; 4 times/d and more than 5 times/d.

Skin carotenoid levels were collected from participants using a reflection spectroscopy device called the "Veggie Meter ${ }^{\circledR}$ ', a valid, non-invasive, objective approximation of fruit and vegetable intake ${ }^{(30)}$. Participants provided finger scans three times (which were averaged) to generate skin carotenoid scores, which range from 0 to 800, with higher scores indicating higher skin carotenoid levels and thus greater FV intake. This tool has been validated against plasma carotenoids in a sample of Black and White participants in eastern North Carolina (correlation between plasma and Veggie Meter ${ }^{\circledR}$ assessed skin carotenoids was $0.71, P<0.0001)^{(30,31)}$. The mean in our prior study was $234 \cdot 2(\mathrm{SD}=86 \cdot 2)^{(32)}$.

\section{Analysis}

Univariate statistics, including means and frequencies, were generated for demographic variables, GIS distance variables, customer shopping patterns and customer dietary behaviours. The GIS-derived distance distribution was right-skewed, so a base 2 log transformation of travel distance and time was generated. For bivariate analysis, we examined correlations between travel distance and travel time with skin carotenoids, and recallbased fruit, vegetable and SSB consumption.

Figure 1 demonstrates the hypothesised associations between distance, shopping behaviours and dietary intake. Distance to the store was hypothesised to be inversely associated with the frequency of shopping such that those who lived close to the small food store shop there more frequently and thus purchased a larger proportion of foods/ beverages from the small food store. Specifically, as noted in Fig. 1, we examined (1) if the frequency of shopping at the small food store, the proportion of all their food purchases coming from the small food store relative to other stores, and previously purchased fruit and vegetables at the small food store were associated with travel distance from the residential address to the small food store (miles and minutes) and (2) if travel distance from the residential address to the small food store (miles and minutes) and frequency of shopping at the small food store were associated with skin carotenoids and self-reported diet (FV and SSB intake).

We used a general logistic regression with random effects to examine the association between shopping frequency using covariates (year, age, sex, race/ethnicity, urban/rural and employment), and travel distance. The small food store was included as a random effect to adjust for potential clustering. Using a linear mixed model, we examined (1) if travel distance (miles and minutes) was associated with skin carotenoids and self-reported diet (FV and SSB intake) and (2) if shopping frequency was associated with skin carotenoids and self-reported diet (FV and SSB intake). Covariates for the full regression models included age (in years), sex (male or female), survey year, race/ethnicity (non-Hispanic White or other race/ethnicity), urban $v$. rural residence and employment (Yes/No). For missing covariate data, pairwise deletion (available-case analysis) was used to minimise data loss, increase power and avoid potential bias in parameters and estimates that can result from listwise deletion methods ${ }^{(33)}$. Additionally, we conducted a mediation analysis to examine the frequency of shopping as a mediator between distance and dietary outcomes while controlling for covariates using SAS Proc Causalmed. We treated shopping frequency as a continuous mediator (SAS Causalmed procedure does not allow categorical mediators with more than two levels). We also tested interactions of urbanicity with shopping frequency and distance to store in all models but found that none were statistically significant, so they were removed from the models. Sensitivity analyses were completed for participants residing within 10 miles ( $n$ 523) and 50 miles ( $n$ 677) of the store for all models, but findings were consistent with models including all participants, so we report results of models containing all participants. All analyses were conducted using SAS version 9.4 (SAS Institutes).

\section{Results}

The characteristics of the study participants are found in Table 1. There were 692 participants with complete

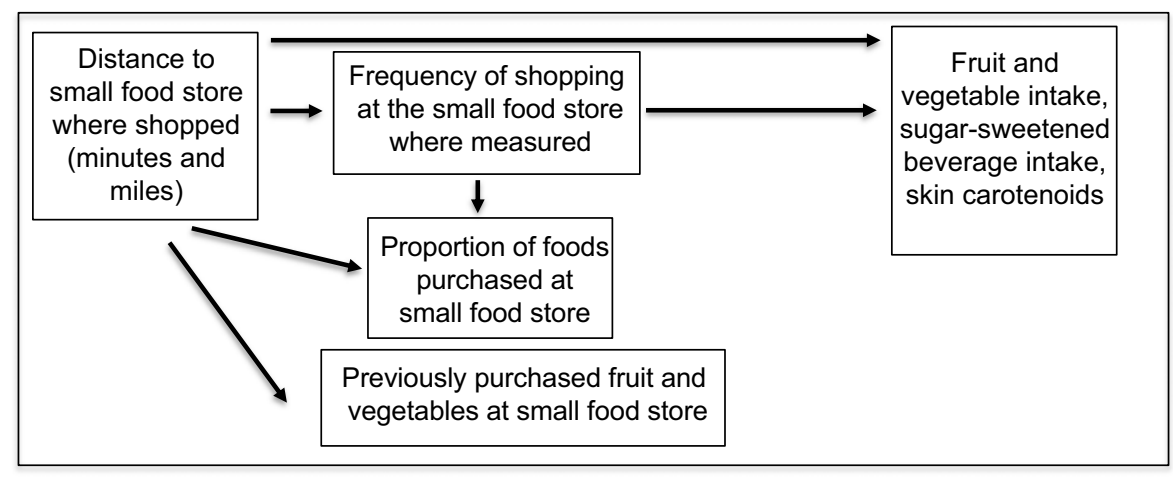

Fig. 1 Tested hypothesised associations between distance, shopping behaviours and dietary intake 
Table 1 Summary of sociodemographic and dietary characteristics of study participants

\begin{tabular}{|c|c|c|c|c|}
\hline Characteristics & $n$ & $\%$ & Mean & SD \\
\hline Age (years) & 690 & & 43.5 & $15 \cdot 2$ \\
\hline BMI $\left(\mathrm{kg} / \mathrm{m}^{2}\right)$ & 678 & & 29.5 & 7.4 \\
\hline Skin carotenoids & 672 & & $235 \cdot 8$ & 84.3 \\
\hline $\begin{array}{l}\text { National Cancer Institute-Screener-assessed fruit } \\
\text { and vegetables (servings/d) }\end{array}$ & 678 & & $3 \cdot 8$ & $3 \cdot 4$ \\
\hline Sugar-sweetened beverages (times/d) & 692 & & $2 \cdot 1$ & $2 \cdot 4$ \\
\hline Distance to small food store (miles) & 692 & & 8.5 & $14 \cdot 0$ \\
\hline Distance to small food store (min) & 692 & & $13 \cdot 7$ & $18 \cdot 3$ \\
\hline \multicolumn{5}{|l|}{ Sex } \\
\hline Female & 296 & $42 \cdot 8$ & & \\
\hline Male & 392 & $56 \cdot 7$ & & \\
\hline Missing & 4 & 0.6 & & \\
\hline \multicolumn{5}{|l|}{ Race } \\
\hline Black & 447 & 64.6 & & \\
\hline White & 171 & $24 \cdot 7$ & & \\
\hline Other & 71 & $10 \cdot 3$ & & \\
\hline Missing & 3 & 0.4 & & \\
\hline \multicolumn{5}{|l|}{ Race and sex } \\
\hline Black/male & 255 & $37 \cdot 2$ & & \\
\hline Black/female & 191 & $27 \cdot 8$ & & \\
\hline White/male & 100 & $14 \cdot 6$ & & \\
\hline White female & 70 & $10 \cdot 2$ & & \\
\hline Other/male & 36 & $5 \cdot 3$ & & \\
\hline Other/female & 34 & 4.9 & & \\
\hline \multicolumn{5}{|l|}{ Income } \\
\hline$<\$ 25000$ & 280 & $40 \cdot 5$ & & \\
\hline$\geq \$ 25000$ & 328 & 47.4 & & \\
\hline Not reported & 84 & $12 \cdot 1$ & & \\
\hline \multicolumn{5}{|l|}{ Education level } \\
\hline At least some college & 258 & $37 \cdot 3$ & & \\
\hline High school graduate or less & 432 & $62 \cdot 4$ & & \\
\hline Missing & 2 & 0.3 & & \\
\hline \multicolumn{5}{|l|}{ Employment status } \\
\hline Currently employed & 406 & $58 \cdot 7$ & & \\
\hline Not working & 281 & $40 \cdot 6$ & & \\
\hline Missing & 5 & 0.7 & & \\
\hline \multicolumn{5}{|l|}{ Distance from home to small food store } \\
\hline Live within 1 mile of store & 251 & $36 \cdot 2$ & & \\
\hline Live $>1$ mile from store & 441 & $63 \cdot 8$ & & \\
\hline \multicolumn{5}{|c|}{ Ever bought fruit and/or vegetables from small food store ( $n$ 492) } \\
\hline Yes & 182 & $37 \cdot 0$ & & \\
\hline No & 294 & 59.8 & & \\
\hline Missing & 16 & $3 \cdot 2$ & & \\
\hline \multicolumn{5}{|c|}{ Shopping frequency at small food store where surveyed } \\
\hline $1-2 x /$ week or less & 227 & $32 \cdot 8$ & & \\
\hline $3-6 x /$ week & 166 & $24 \cdot 0$ & & \\
\hline $1 \mathrm{x} / \mathrm{d}$ or more & 283 & $40 \cdot 9$ & & \\
\hline Missing & 16 & $2 \cdot 3$ & & \\
\hline \multicolumn{5}{|c|}{$\begin{array}{l}\text { Self-reported proportion of foods purchased at the small food } \\
\text { store ( } 2019 \text { sample only, } n 146)\end{array}$} \\
\hline All or most of my foods & 17 & $11 \cdot 7$ & & \\
\hline More than half & 16 & $11 \cdot 0$ & & \\
\hline About half & 31 & $21 \cdot 2$ & & \\
\hline Less than half & 31 & $21 \cdot 2$ & & \\
\hline A very small proportion & 51 & 34.9 & & \\
\hline
\end{tabular}


$40.9 \%$ shopping one or more times per day. Of the year 2019 participants who answered the question regarding the proportion of foods purchased at the store, $34.9 \%$ answered that a 'very small proportion of my food and beverages comes from this corner store', with $11.7 \%$ responding that 'All or most of my food and beverages' were purchased at that small food store. Almost half of the year 2019 participants (43.9\%) stated that half or more of their food and beverages come from the store where surveyed.

\section{Customer diet}

Participants reported consuming an average of $3.8(\mathrm{SD}=3.4)$ servings of fruits and vegetables per day (based on the NCI FV screener) and consuming SSB $2 \cdot 1(\mathrm{SD}=2 \cdot 4)$ times per day. The average Veggie Meter ${ }^{\circledR}$ reading was $235 \cdot 8(\mathrm{SD}=84 \cdot 3)$.

\section{Distance to the store}

The average distance to the store where surveyed from the participant's home was $8.5(\mathrm{SD}=14.0)$ miles. A little over one-third $(36.2 \%)$ of participants lived within one mile of the store, and about one-quarter $(24.4 \%)$ of participants lived greater than 10 miles from the store. The range was from 0.01 to 98.9 miles. The average travel time to the store where participants were surveyed from their home was $13.7 \mathrm{~min}(\mathrm{SD}=18.2)$, with an average travel time of $9.3 \mathrm{~min}(\mathrm{SD}=14.3)$ for urban participants, and $21.7 \mathrm{~min}$ $(\mathrm{SD}=21 \cdot 6)$ for rural participants.

\section{Distance to the store and demographic variables}

A summary of the relationship between distance to the store and demographic variables is found in Table 2. In unadjusted bivariate analyses, Black participants lived significantly closer to the store than White or 'other' racial/ethnic groups in both miles $(P<.0001)$ and minutes $(P<.0001)$. Those making less than $\$ 25000 /$ year lived significantly closer to the store than those making $\geq \$ 25000 /$ year $(P<.0001$ for miles and minutes). Participants who were not employed lived significantly closer to the store than employed participants ( $P<.0001$ for miles and minutes).

\section{Distance to the store and store-level variables}

There was a statistically significant difference in distance between the residential address and the store in miles $(P<.0001)$ and minutes $(P<.0001)$ for participants shopping at rural $v$. urban stores, with rural stores having customers who lived further from the store where participants were surveyed (Table 2). The mean distance to the store for urban participants was 6.0 miles $(\mathrm{SD}=12.9)$, and for rural participants, the mean distance to the store was 14.4 miles ( $\mathrm{SD}=14 \cdot 6$ ).

\section{Associations between distance to the store and shopping patterns}

A summary of the results of the associations between distance to the store and shopping patterns is included in
Table 2 Associations between distance and customer sociodemographic variables, store-level variables and shopping behaviours among customers

\begin{tabular}{|c|c|c|c|}
\hline & \multicolumn{3}{|c|}{ Miles } \\
\hline & Distance & SD & $P$ \\
\hline \multicolumn{4}{|l|}{ Sociodemographic variables } \\
\hline \multicolumn{4}{|l|}{ Race ( $n$ 689) } \\
\hline Black & $6 \cdot 2$ & $11 \cdot 8$ & $<\cdot 0001$ \\
\hline White & $14 \cdot 6$ & $17 \cdot 4$ & \\
\hline Other & 8.5 & 13.7 & \\
\hline \multicolumn{4}{|l|}{ Income (n 692) } \\
\hline$<\$ 25000$ & $6 \cdot 1$ & $12 \cdot 1$ & $<\cdot 0001$ \\
\hline$\$ 25000+$ & $11 \cdot 2$ & $15 \cdot 5$ & \\
\hline Not reported & $5 \cdot 8$ & $11 \cdot 8$ & \\
\hline \multicolumn{4}{|l|}{ Employment ( $n$ 687) } \\
\hline Not employed & $5 \cdot 8$ & $11 \cdot 8$ & $<.0001$ \\
\hline Employed & $10 \cdot 4$ & $15 \cdot 1$ & \\
\hline \multicolumn{4}{|l|}{ Store-level variables } \\
\hline \multicolumn{4}{|l|}{ Urbanicity (n 692) } \\
\hline Urban & $6 \cdot 0$ & $12 \cdot 9$ & $<\cdot 0001$ \\
\hline Rural & 14.4 & $14 \cdot 6$ & \\
\hline \multicolumn{4}{|l|}{ Shopping behaviours } \\
\hline \multicolumn{4}{|c|}{$\begin{array}{l}\text { Previously bought fruit or vegetables } \\
\text { at participating store ( } n \text { 476) }\end{array}$} \\
\hline Yes & $4 \cdot 6$ & $8 \cdot 6$ & $<\cdot 0001$ \\
\hline No & $10 \cdot 0$ & $15 \cdot 3$ & \\
\hline Shopping frequency ( $n$ 676) & & & $<\cdot 0001$ \\
\hline $1-2 x$ week or less & $13 \cdot 1$ & $16 \cdot 1$ & \\
\hline $3-6 x$ week & $7 \cdot 2$ & $12 \cdot 8$ & \\
\hline $1 \mathrm{x} / \mathrm{d}$ or more & $4 . \overline{9}$ & $10 \cdot 7$ & \\
\hline
\end{tabular}

Table 2. Participants that had previously bought FV at the store lived a shorter distance in miles $(P<.0001)$ and minutes $(P<.0001)$ from the store than those who had not previously bought FV at the store. There was a statistically significant association between shopping frequency and the distance to the store in miles $(P=<.0001)$ and minutes $(P=<.0001)$, indicating that participants who lived closer to the store more frequently shopped at the store.

\section{Associations between distance to the store and proportion of foods purchased}

Those with a higher proportion of all their food purchases coming from the small food store relative to other stores lived closer to the store (2019 sample only, $n$ 146), though this relationship was not statistically significant $((F(4,141)=$ $2 \cdot 10, P=0 \cdot 08)$, Table 3).

\section{Distance to the store and frequency of shopping}

In a general logistic regression model controlling for year, store, age, sex, race/ethnicity, employment and rural $v$. urban residence, frequency of shopping at the small food store where surveyed was inversely associated with distance in miles to the store where surveyed such that individuals ( $n$ 664) who lived further from the store shopped less frequently (estimate $=0 \cdot 22, \mathrm{sE}=0.058, P=<0.001$ for $3-6 \mathrm{x} /$ week $v$. $1-2 \mathrm{x} /$ week or less) (estimate $=-0 \cdot 16$, 
Accessibility and diet in small food store customers

Table 3 Summary of measures of distance to the small food store where shopping from home (miles, minutes) and proportion of foods and beverages purchased among $n 146$ customers self-reporting in 2019

\begin{tabular}{|c|c|c|c|}
\hline \multirow{2}{*}{$\begin{array}{l}\text { Proportion of foods and beverages } \\
\text { purchased }\end{array}$} & \multirow[b]{2}{*}{$n$} & \multicolumn{2}{|c|}{ Miles* } \\
\hline & & Mean & SD \\
\hline All or most of my food and beverages & 17 & $2 \cdot 4$ & $2 \cdot 4$ \\
\hline More than $\mathrm{h}$ & 16 & 7.6 & $12 \cdot 9$ \\
\hline About half & 31 & 4.3 & 6.9 \\
\hline Less than half & 31 & $6 \cdot 0$ & 8.8 \\
\hline A very small proportion & 51 & $10 \cdot 5$ & $18 \cdot 3$ \\
\hline
\end{tabular}

${ }^{\star} F(4,141)=2 \cdot 10, P=0.08$.

$\mathrm{SE}=0.049, P=0.001$ for $1 \mathrm{x} / \mathrm{d}$ or more $v \cdot 3-6 \mathrm{x} /$ week) (Table 4).

\section{Frequency of shopping and dietary measures}

In a linear mixed model controlling for year, store, age, sex, race/ethnicity, employment status, rural $v$. urban residence and distance to store, participants ( $n$ 644) who shopped 1-2 per week or less had significantly higher skin carotenoids compared to those who shopped 3-6 times per week (estimate $=20 \cdot 4, \mathrm{SE}=8 \cdot 7, P=0 \cdot 02$ ) (Table 4). There were no statistically significant differences found across levels of shopping frequency with self-reported NCI FV intake ( $n$ 651) or SSB intake ( $n$ 664). (Table 4)

\section{Distance to the store and dietary measures}

In the linear mixed model with skin carotenoids as the dependent variable of interest ( $n$ 644), controlling for year, store, age, sex, race/ethnicity, employment status, rural $v$. urban residence and shopping frequency, skin carotenoids were positively associated with distance to the store from home in miles (estimate $=3 \cdot 86, \mathrm{sE}=1 \cdot 61, P=0 \cdot 02$ ) (Table 4). There were no statistically significant associations between self-reported FV intake ( $n$ 651) and SSB intake ( $n$ 644) and distance to the store ( $P=0.35$ and $P=0 \cdot 17$, respectively).

\section{Shopping frequency as a mediator between distance and dietary measures}

The percentage mediated effect of distance to the store was $6.0 \%(P=0.55)$ on skin carotenoids, $19.9 \%(P=0.49)$ on NCI FV intake and $-109.0 \%(P=0.43)$ on sugary beverage intake, indicating that shopping frequency was not found to be a statistically significant mediator between distance and dietary measures. Thus, our original hypothesis of shopping frequency being a mediator between distance and dietary measures was not supported.

\section{Discussion}

Customers in our study who lived closer to the small food stores had lower incomes, were more likely to be unemployed, shopped more frequently at the store and had

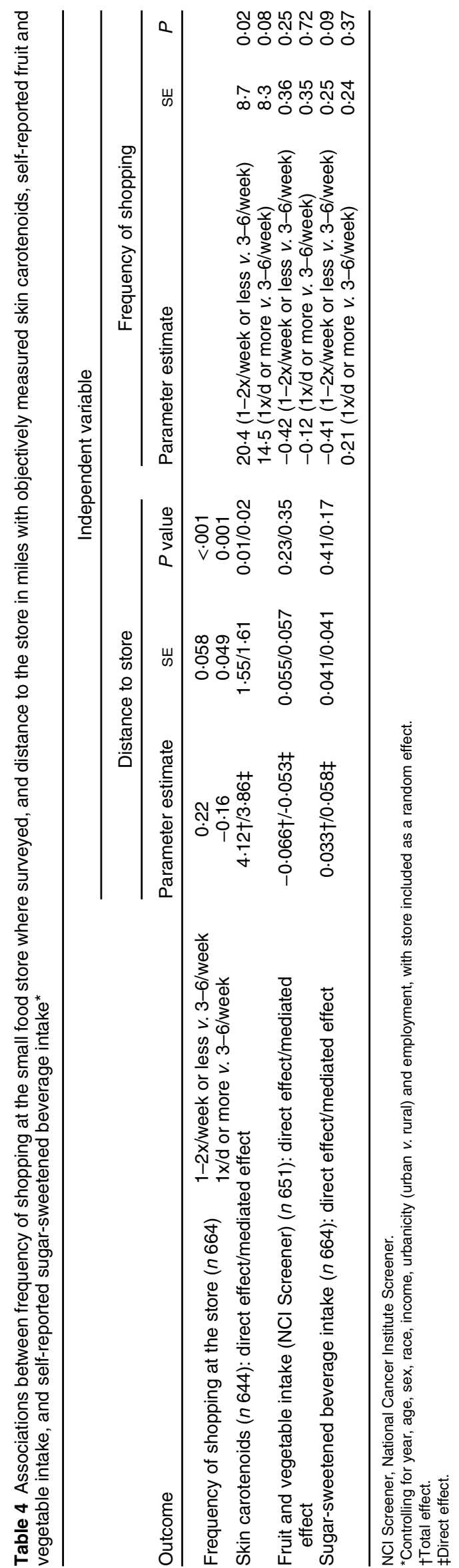


lower skin carotenoids (indicative of lower carotenoid fruit and vegetable consumption), yet they were more likely to have previously purchased FV at the store where surveyed. This could be due to increased exposure from more frequent shopping at the store and possibly relying on the store for most or all of their household food and beverage needs. The mean carotenoids score $(235 \cdot 8$ ( $\mathrm{SD}=84 \cdot 3)$ ) was similar to that in our prior study of an earlier time point $(234.2(\mathrm{SD}=86 \cdot 2))$. Our findings are also aligned with the findings of others regarding mean Veggie Meter ${ }^{\circledR}$ scores of about 200-250 $34-37)$. The Veggie Meter score is suggestive of about 4 weeks of exposure ${ }^{(38)}$. The fact that carotenoid scores were lower for those that lived closer to the small store, yet they were more likely to have previously purchased FV at the store where surveyed, may suggest that without access to FV at small stores, skin carotenoid levels could be even lower among this population. The lower carotenoid scores among those who live closer and shop more frequently at the small store where surveyed could indicate that these residents are getting most, or all of their household food needs met at small stores. This could also suggest they are more dependent on the store for their basic shopping due to a limited income and the need to shop more proximally to their residence rather than at stores with a wider selection. With limited food availability at the small store, they were less likely to get fruits and vegetables and thus had lower carotenoid scores. This supports efforts to make the food environment in such stores as healthy as possible. In a previous study of skin carotenoid status and distance to and frequency of shopping among supermarket customers, we found no statistically significant difference in skin carotenoids by frequency of shopping or by distance to the store, though we did find that proximity to less healthy stores such as convenience stores and small grocery stores was associated with lower skin carotenoid levels ${ }^{(18)}$. These findings suggest that public health efforts should continue to promote healthier foods and beverages in similar small food stores.

We found that people living closer to the store where they were surveyed tended to shop there more often and purchased the highest proportion of foods from that store when compared to customers living further from the store. This idea is consistent with the distance decay theory, which suggests that the interaction among two entities decreases as distance increases ${ }^{(39)}$. Our finding that shopping frequency was not a statistically significant mediator between distance to the store and dietary outcomes, but that frequency was statistically significantly associated with distance, may suggest that the influence of distance and frequency are interconnected but also distinctly relevant. Future research should examine this more closely. While previous research has suggested that the closest food retail venue (particularly for supermarkets) is not necessarily where customers most frequently shop ${ }^{(40)}$, partially due to the complexity of food shopping decisions ${ }^{(41)}$, it does appear that proximity to small food stores, in particular, could be an influential factor in usage ${ }^{(18)}$. We found that those making less than $\$ 25000 /$ year and those who were unemployed lived closer to the small food store where surveyed, which suggests that these types of stores are readily accessible to people with lower socio-economic status, who may also have disproportionately worse health outcomes compared to those of higher socioeconomic status $^{(42)}$.

In addition to proximity being associated with shopping frequency, our results suggest that Black male participants (37.2\% of our sample) were frequent shoppers at the small food stores. This is a priority population since they bear a disproportionate burden of chronic disease ${ }^{(43)}$ and premature mortality ${ }^{(43)}$ in the USA but have received relatively little attention in the public health and food access literature. Future research should try and better understand the influence of food access, particularly in small food stores, on Black male shopping and dietary behaviours.

The strengths of the study include the large sample size and the use of both objective and recall-based dietary measurements, the use of GIS to derive multiple objective measures of proximity based on road network data and the examination of shopping behaviours and preferences in combination with GIS-derived objective access measures. Despite its strengths, this study has limitations that should be acknowledged when interpreting these results. We used a convenience sample and a cross-sectional study design, which may limit generalisability and limit the ability to determine causation. There may be selection bias based on the customers and stores who chose to participate (those more likely to participate may also be more interested in health or the participant incentive) and those with complete address information. We found that those with complete addresses shopped more frequently at the store and had higher sugary beverage consumption, so our results for these variables could be biased away from the null. In a few cases, customers completed surveys without purchasing a food or beverage item. Also, participants were encouraged but not required to wash their hands before skin carotenoids were assessed using the Veggie Meter ${ }^{\circledR}$, which could lead to less accurate readings ${ }^{(43)}$. We did not assess physical access from other important locations of daily life (like work, childcare and other shopping), nor do we know the mode of transportation used for the customer's visit to the store. We also did not have information about shopping patterns at other food venues.

\section{Conclusions}

This study contributes to our understanding of food accessibility, shopping patterns and dietary outcomes among small food store customers using objectively measured distance and dietary outcomes. We found that living closer to the small food store where individuals shop is associated with more frequent shopping and may also be associated 
with lower dietary quality. This provides evidence of the potential influence of small food stores on dietary behaviours, particularly for those populations who are more reliant on this store type for their food and beverage purchases. From an intervention and policy perspective, our findings support attempts to promote healthier purchases in small food stores by increasing the availability of healthier food options, given that individuals of lower socio-economic status live closer to and shop more frequently at these stores. Future interventions and healthy food store programme and policy planning should take into account these complex relationships to optimise public health impact.

\section{Acknowledgements}

Acknowledgements: We are grateful for all the work of ECU and UNCG graduate assistants for all their work in data collection. Financial support: Support for this article was provided by the Robert Wood Johnson Foundation's Policies for Action programme, Grant number 76101. The views expressed here do not necessarily reflect the views of the Foundation. Conflict of interest: The authors have no conflicts of interest. Authorship: J.T.M. and S.J.P. conceptualised the study, oversaw data collection and led manuscript preparation. Q.W. analysed data and assisted with manuscript preparation; A.P.R. helped to oversee data collection and assisted with manuscript preparation. K.P.T., M.N.L., R.A.B. and A.S.A. assisted with overall study design and conceptualisation, manuscript preparation and revision. All authors reviewed and approved the version of the manuscript as published. Ethics of human subject participation: This study was conducted according to the guidelines laid down in the Declaration of Helsinki and all procedures involving research study participants were approved by the East Carolina University Institutional Review Board \#UMCIRB 16-002420. Verbal informed consent was obtained from all participants.

\section{References}

1. Beaulac J, Kristjansson E \& Cummins S (2009) A systematic review of food deserts, 1966-2007. Prev Chronic Dis 6, A105.

2. Ver Ploeg M, Breneman V, Farrigan T et al. (2009) USDA ERS Access to Affordable and Nutritious Food-Measuring and Understanding Food Deserts and Their Consequences: Report to Congress. Available at https://www.ers.usda.gov/ publications/pub-details/?pubid=42729 (accessed March 2020).

3. Caspi CE, Sorensen G, Subramanian SV et al. (2012) The local food environment and diet: a systematic review. Health Place 18, 1172-1187.

4. Gibson DM (2011) The neighborhood food environment and adult weight status: estimates from longitudinal data. $A m J$ Public Health 101, 71-78.

5. Cannuscio CC, Weiss EE, Asch DA (2010) The contribution of urban foodways to health disparities. J Urban Health $\mathbf{8 7}$, 381-393.

6. Pinard CA, Byker Shanks C, Harden SM et al. (2016) An integrative literature review of small food store research across urban and rural communities in the U.S. Prev Med Rep 3, 324-332.

7. Glanz K, Yaroch A (2004) Strategies for increasing fruit and vegetable intake in grocery stores and communities: policy, pricing, and environmental change. Prev Med 2, S75-S80.

8. Langellier BA, Garza JR, Prelip ML et al. (2013) Corner store inventories, purchases, and strategies for intervention: a review of the literature. Californian J Health Promot 11, 1-13.

9. Laska MN, Borradaile KE, Tester J et al. (2010) Healthy food availability in small urban food stores: a comparison of four US cities. Public Health Nutr 13(7), 1031-1035. Available at https://www.cambridge.org/core/journals/public-healthnutrition/article/healthy-food-availability-in-small-urbanfood-stores-a-comparison-of-four-us-cities/1A5EF947838A11 A355BA8B6F4394C586 (accessed March 2020).

10. Lucan SC, Karpyn A, Sherman S (2010) Storing empty calories and chronic disease risk: snack-food products, nutritive content, and manufacturers in Philadelphia corner stores. J Urban Health 87, 394-409.

11. Pitts SB, Bringolf KR, Lawton KK et al. (2013) Formative evaluation for a healthy corner store initiative in Pitt County, North Carolina: assessing the rural food environment, part 1. Prev Chronic Dis 10, E121-E121.

12. Liese AD, Weis KE, Pluto D et al. (2007) Food store types, availability, and cost of foods in a rural environment. $J \mathrm{Am}$ Diet Assoc 107, 1916-1923.

13. McGuirt JT, Pitts SBJ, Ammerman A et al. (2015) A mixed methods comparison of urban and rural retail corner stores. AIMS Public Health 2, 554-582.

14. Gittelsohn J, Rowan M, Gadhoke P (2012) Interventions in small food stores to change the food environment, improve diet, and reduce risk of chronic disease. Prev Chronic Dis 9. E59.

15. Jilcott Pitts SB, Wu Q, Truesdale KP et al. (2018) One-year follow-up examination of the impact of the North Carolina healthy food small retailer program on healthy food availability, purchases, and consumption. Int J Environ Res Public Health 15, 2681.

16. Ortega AN, Albert SL, Chan-Golston AM et al. (2016) Substantial improvements not seen in health behaviors following corner store conversions in two Latino food swamps. BMC Public Health 16, 389.

17. Langellier BA (2012) The food environment and student weight status, Los Angeles County, 2008-2009. Prev Chronic Dis 9, E61.

18. McGuirt JT, Jilcott Pitts SB, Gustafson A (2018) Association between spatial access to food outlets, frequency of grocery shopping, and objectively-assessed and self-reported fruit and vegetable consumption. Nutrients 10, 1974.

19. Kristal AR, Andrilla CHA, Koepsell TD et al. (1998) Dietary assessment instruments are susceptible to intervention-associated response set bias. J Am Diet Assoc 98, 40-43.

20. Harnack L, Himes JH, Anliker J et al. (2004) Interventionrelated bias in reporting of food intake by fifth-grade children participating in an obesity prevention study. Am J Epidemiol 160, 1117-1121.

21. Miller TM, Abdel-Maksoud MF, Crane LA et al. (2008) Effects of social approval bias on self-reported fruit and vegetable consumption: a randomized controlled trial. Nutr J 7, 18.

22. Pitts SBJ, Jahns L, Wu Q et al. (2018) A non-invasive assessment of skin carotenoid status through reflection spectroscopy is a feasible, reliable and potentially valid measure of fruit and vegetable consumption in a diverse community sample. Public Health Nutr 21(9), 1664-1670. Available at https://www.cambridge.org/core/journals/public-healthnutrition/article/noninvasive-assessment-of-skin-carotenoidstatus-through-reflection-spectroscopy-is-a-feasible-reliableand-potentially-valid-measure-of-fruit-and-vegetable-consumptionin-a-diverse-community-sample/D414B0FB195D1F7AE76E10260 DC2E2ED (accessed March 2020). 
23. North Carolina Department of Agriculture and Consumer Services (2019) Healthy Food Small Retailer Program. Available at https://www.ncagr.gov/markets/healthyFood SmallRetailer/index.htm (accessed March 2020).

24. Ver Ploeg M, Breneman V \& Rhone A (2017) USDA ERS-Food Access Research Atlas. Available at https://www.ers.usda. gov/data-products/food-access-research-atlas/ (accessed March 2020).

25. United States Department of Agriculture Economic Research Service (2019) Data Feature: Mapping Food Deserts in the U.S. Available at https://www.ers.usda.gov/amber-waves/ 2011/december/data-feature-mapping-food-deserts-in-the-us/ (accessed March 2020).

26. Ermakov IV, Whigham LD, Redelfs AH et al. (2016) Skin carotenoids as biomarker for vegetable and fruit intake: validation of the reflection-spectroscopy based "Veggie meter." FASEB J 30, 409.3.

27. BatchGeo: Create maps from your data. Available at https:// batchgeo.com/ (accessed March 2020).

28. National Cancer Institute (2020) Fruit \& Vegetable Screeners in the Eating at America's Table Study (EATS): Instruments. Available at https://epi.grants.cancer.gov/diet/screeners/ fruitveg/instrument.html (accessed March 2020).

29. Centers for Disease Control and Prevention (2020) Behavioral Risk Factor Surveillance System (BRFSS). Available at https:// www.cdc.gov/brfss/index.html (accessed March 2020).

30. Pitts SBJ, Jahns L, Wu Q et al. (2018) A non-invasive assessment of skin carotenoid status through reflection spectroscopy is a feasible, reliable and potentially valid measure of fruit and vegetable consumption in a diverse community sample. Public Health Nutr 21, 1664-1670.

31. Jahns L, Johnson LK, Conrad Z et al. (2019) Concurrent validity of skin carotenoid status as a concentration biomarker of vegetable and fruit intake compared to multiple 24-h recalls and plasma carotenoid concentrations across one year: a cohort study. Nutr J 18(1), 78. Available at https://link. springer.com/article/10.1186/s12937-019-0500-0 (accessed March 2020).

32. Jilcott Pitts SB, Wu Q, Truesdale KP et al. (2017) Baseline assessment of a healthy corner store initiative: associations between food store environments, shopping patterns, customer purchases, and dietary intake in Eastern North Carolina. Int J Environ Res Public Health 14, 1189.

33. Statistics Solutions (2013) Missing Data: Listwise $v$. Pairwise Statistics Solutions. Available at https://www.statistics solutions.com/missing-data-listwise-vs-pairwise/ (accessed March 2020).
34. Hill C, O'Brien D, Paschall M et al. (2019) Validity of reflection spectroscopy as a biomarker of vegetable and fruit intake in a Yu'pik Alaska native population (P18-124-19). Curr Dev Nutr 3, Suppl. 1, nzz039-P18.

35. Bakırc1-Taylor AL, Reed DB, McCool B et al. (2019) mHealth improved fruit and vegetable accessibility and intake in young children. $J$ Nutr Educ Behav 51, 556-566.

36. May K, Jilcott Pitts S, Stage VC et al. (2020) Use of the Veggie Meter ${ }^{\circledR}$ as a tool to objectively approximate fruit and vegetable intake among youth for evaluation of preschool and school-based interventions. J Hum Nutr Diet. Available at https://onlinelibrary.wiley.com/doi/full/10.1111/jhn.12755? casa_token $=$ f0hnYUwnwzIAAAAA\%3AviPMqsco2tFXMMor7oeY2H7jgW16R6Sf1TljZYmnCbXKcsw0LFZKvKrMNIfZ044WnrOP 53T04kmaemdtw (accessed March 2020).

37. Erickson T, Dickinson S, Golzarri-Arroyo L et al. (2020) Effect of handwashing on skin carotenoid measurements using pressure-mediated reflectance spectroscopy. Curr Dev Nutr 4, Suppl. 2, 103. Available at https://academic.oup. com/cdn/article/4/Supplement_2/103/5845143 (accessed March 2020).

38. Jahns L, Johnson LK, Mayne ST et al. (2014) Skin and plasma carotenoid response to a provided intervention diet high in vegetables and fruit: uptake and depletion kinetics. Am J Clin Nutr 100, 930-937.

39. Pun-Cheng LSC (2016) Distance decay. In International Encyclopedia of Geography, pp. 1-5. Hoboken, NJ, USA: John Wiley \& Sons, Ltd.

40. Cannuscio CC, Tappe K, Hillier A et al. (2013) Urban food environments and residents' shopping behaviors. Am J Prev Med 45, 606-614.

41. Cannuscio CC, Hillier A, Karpyn A et al. (2014) The social dynamics of healthy food shopping and store choice in an urban environment. Soc Sci Med 122, 13-20.

42. Stringhini S, Carmeli C, Jokela M et al. (2017) Socioeconomic status and the $25 \times 25$ risk factors as determinants of premature mortality: a multicohort study and meta-analysis of 1.7 million men and women. The Lancet 389(10075), 12291237. Available at https://www.thelancet.com/journals/ lancet/article/PIIS0140-6736(16)32380-7/fulltext (accessed March 2020).

43. Baciu A, Negussie Y, Geller A et al. (2017) The state of health disparities in the United States. In Communities in Action: Pathways to Health Equity. National Academies Press (US). Available at https://www.ncbi.nlm.nih.gov/books/ NBK425844/ (accessed March 2020). 